\title{
Perfusion mapping with Tc-HMPAO in cerebral haematomas
}

\author{
Marc Rousseaux, Marc Steinling, Damien Huglo, Andre Mazingue, Pascal Barbaste
}

\begin{abstract}
The cerebral distribution of HMPAO was mapped tomographically by SPECT in 20 patients with an intra cerebral haematoma. The images were assessed visually and by an analysis of an asymmetry index (AI) for various cerebral areas. Visual inspection identified the lesion in each of the 20 cases. Reduced tracer activity and abnormal AI were consistent findings. Remote effects (diaschisis) were also observed in the adjacent (19 cases) and frontal (14 cases) cortex, and in the controlateral cerebellum (16 cases). Sequential studies at 60,150 and 300 minutes in 10 patients showed remarkably stable patterns. HMPAO maps were compared with cerebral blood flow (CBF) measured with 133 Xenon $\left({ }^{133} \mathrm{Xe}\right)$ in eight cases. The two methods showed similar results in the region of a lesion, but remote effects were more obvious with the ${ }^{133} \mathrm{Xe}$ in two patients.
\end{abstract}

Measurement of cerebral blood flow (CBF) by Xenon techniques and mapping of the cerebral distribution of radioactive tracers, such as 123 Iodo-Amphetamine, by single photon emission tomography (SPECT) have proved useful in the evaluation of intracerebral haematomas. ${ }^{1-4}$ These studies showed low rates of flow or low uptake of tracer in the lesion and its immediate vicinity, but also showed remote effects at other cortical sites and/or in the cerebellum. These may contribute to the neurological and neuropsychological deficits. ${ }^{35}$

In addition, sequential studies with IAMP in patients with a stroke have shown late redistribution of the tracer. This has been proposed to provide an index of a cellular viability $^{6}$ but this concept is controversial. ${ }^{78}$

The aim of this study was to evaluate the use of technetium-99m hexamethylpropyleneamine-oxyme (99m-Tc-HMPAO) in cerebral haematomas. We wanted to discover: 1) The value of HMPAO in demonstrating the lesion and any remote cortical or cerebellar effects; 2) The relationship between remote diaschisis and neurological or neuropsychological deficits; 3) The evolution of the tracer distribution with time; and 4) How HMPAO maps compared with conventional CBF evaluation with ${ }^{133} \mathrm{X}$.

\section{Patients and methods}

\section{1) Study of the HMPAO distribution}

We studied twenty patients who were shown by CT to have a supratentorial intracerebral haematoma (11 on the left and nine on the right side) (table). There were nine females and 11 males, and the mean age was 62 years (range 43-82). Each patient had a stroke, considered to be "spontaneous" or secondary to arterial hypertension. The sites involved were: centrum semi ovalum and lenticular nucleus (eight cases); lenticular nucleus and internal capsule (five cases); thalamus and internal capsule (four cases); thalamus (three cases). The size of each haematoma was assessed by calculating the volume (in $\mathrm{cm}^{3}$ ) of an elipsoid whose diameter was measured in the three spatial axes.

The distribution of HMPAO was studied from one to 95 days after the onset of the stroke, using the Tomomatic 64 systems (Medimatic, Copenhagen). The examination was performed after a 15 minute adaptation period, with the subject lying in the apparatus, in the dark and in silence. The HMPAO was injected IV in a dose of 7.4 $\mathrm{MBq} / \mathrm{Kg}$. The tomograms were analysed on three slices, $15 \mathrm{~mm}$ thick, parallel to the orbito-meatal plane $(\mathrm{OM}+1,+5,+9)$. The recordings were realised five minutes after the injection in 10 patients and 60 minutes after in 10 others.

Two different analyses were performed: 1) A qualitative visual analysis was made by two independent observers to identify the lesion and estimate the "remote" effects ("diaschisis") in the ipsilateral non contiguous cortex, frontal ipsilateral cortex and controlateral cerebellum. Localised hypoactivities were labelled "certain", "questionable" or "absent". 2) A quantitative analysis, making use of a normalised calculation of the activity and asymmetry index (AI).

$\left(\mathrm{AI}=\frac{\text { "normal side" activity - "lesion side" activity }}{\text { "normal side" activity + "lesion side" activity }} \times 200\right)$ This was done in the lesion area, in the ipsilateral (non contiguous) cortex, in the frontal cortex and in the cerebellum. The AI values were afterwards compared with the reference values obtained in six normal subjects. ${ }^{9}$

2) Comparison of the results of the clinical and $C T$ and HMPAO study

For each patient, we assessed motor and sensory deficits (0: absent, 1 : moderate, 2 : major), 
Table Presentation of the 20 patients. Abbreviations for the site of the lesions: $C S O=$ centrum semi ovalum; $L N=$ lenticular nucleus; $I C=$ internal capsule; $T H=$ thalamus. The autonomy in daily living $(A D L)$ was assessed with the Barthel's index.

\begin{tabular}{|c|c|c|c|c|c|c|c|c|c|}
\hline Sex & Age & $\begin{array}{l}\text { Lesion } \\
\text { site }\end{array}$ & Side & $\begin{array}{l}\text { Volume } \\
\left(\mathrm{cm}^{3}\right)\end{array}$ & Days & $A D L$ & $\begin{array}{l}\text { Motor } \\
\text { deficit }\end{array}$ & $\begin{array}{l}\text { Sensory } \\
\text { deficit }\end{array}$ & $\begin{array}{l}\text { Psychological } \\
\text { deficit }\end{array}$ \\
\hline $\mathbf{M}$ & 57 & $\mathrm{TH}$ & L & $2 \cdot 7$ & 21 & 20 & 1 & 0 & 2 \\
\hline $\mathbf{M}$ & 73 & $\mathrm{TH}+\mathrm{IC}$ & $\mathrm{L}$ & $3 \cdot 5$ & 34 & 5 & 2 & 2 & 2 \\
\hline $\mathbf{M}$ & 51 & $\mathrm{LN}+\mathrm{IC}$ & $\mathbf{R}$ & $6 \cdot 5$ & 10 & 5 & 2 & 2 & 2 \\
\hline M & 62 & $\mathrm{TH}+\mathrm{IC}$ & $\mathbf{R}$ & $10 \cdot 0$ & 29 & 35 & 1 & 2 & 2 \\
\hline M & 55 & $\mathrm{LN}+\mathrm{IC}$ & $\mathbf{R}$ & $10 \cdot 7$ & 12 & 80 & 1 & 0 & 2 \\
\hline M & 73 & CSO & $\mathrm{L}$ & 13.5 & 16 & 25 & 2 & 1 & 2 \\
\hline $\mathrm{F}$ & 43 & $L N+I C$ & $\overrightarrow{\mathbf{R}}$ & $14 \cdot 0$ & 26 & 0 & 2 & $i$ & 2 \\
\hline $\mathbf{M}$ & 53 & $\mathrm{TH}+\mathrm{IC}$ & $\mathrm{L}$ & 15.5 & 95 & 75 & 1 & 2 & 1 \\
\hline$M$ & 75 & $\mathrm{TH}+\mathrm{IC}$ & $\overline{\mathrm{L}}$ & 15.9 & 53 & 0 & 2 & 2 & 2 \\
\hline $\mathbf{F}$ & 65 & $\mathrm{CSO}+\mathrm{LN}$ & $\overline{\mathbf{R}}$ & $16 \cdot 7$ & 90 & 25 & 2 & 2 & 2 \\
\hline $\mathrm{F}$ & 66 & $\mathrm{CSO}+\mathrm{LN}$ & $\mathbf{R}$ & $17 \cdot 4$ & 45 & 55 & 2 & 2 & 1 \\
\hline $\mathbf{M}$ & 79 & TH & $\mathbf{R}$ & 17.5 & 35 & 35 & 1 & 2 & 2 \\
\hline $\mathrm{F}$ & 59 & $\mathrm{LN}+\mathrm{IC}$ & $\mathrm{L}$ & $19 \cdot 0$ & 1 & 15 & 2 & 2 & 2 \\
\hline $\mathrm{F}$ & 54 & $\overline{L N}+\mathrm{IC}$ & $\bar{L}$ & $24 \cdot 0$ & 26 & 80 & 1 & 1 & 1 \\
\hline $\mathbf{F}$ & 82 & TH & $\bar{L}$ & $24 \cdot 2$ & 35 & 45 & 1 & 1 & 1 \\
\hline F & 50 & $\mathrm{CSO}+\mathrm{LN}$ & $\mathrm{L}$ & $32 \cdot 4$ & 18 & 10 & 2 & 2 & 1 \\
\hline$M$ & 48 & $\mathrm{CSO}+\mathrm{LN}$ & L & $45 \cdot 7$ & 28 & 30 & 2 & 2 & 1 \\
\hline F & 61 & $\mathrm{CSO}+\mathrm{LN}$ & $\vec{L}$ & $77 \cdot 0$ & 20 & 5 & 2 & 2 & 2 \\
\hline M & 72 & $\mathrm{CSO}+\mathrm{LN}$ & $\mathbf{R}$ & $79 \cdot 2$ & 32 & 10 & 2 & 2 & 2 \\
\hline $\mathrm{F}$ & 66 & $\mathrm{CSP}+\mathrm{LN}$ & R & $174 \cdot 8$ & 37 & 25 & 2 & 2 & 2 \\
\hline
\end{tabular}

the severity of neuropsychological problems, such as, aphasia or neglect (0: absent, 1 : moderate, 2: major), the severity of aphasia (from 0-6 with the "severity" subtest of the Boston Diagnostic Aphasia Examination in 11 patients). We used the Barthel index ${ }^{10}$ to assess independence in daily living, on a score ranging from $0-100$.

Correlations were sought between the clinical data, the age of the patient, motor, sensory and neuropsychological deficits, Barthel's index, and the AI in three areas: haematoma, ipsilateral cortex, and frontal cortex. The Spearman test was used, with the Bonferroni correction ${ }^{11}$ to assess significance $(0.017=0.050 / 3$ for each clinical variable $)$.

\section{3) Analysis of the time course of $H M P A O$ activity}

This was performed in 10 consecutive patients (cases 11-20), six men and four women (mean age: 66 years). We measured the initial activity for 10 minutes after injection with a classic gamma camera (Gamma Tome 1, CGR, Paris). We then used the Tomomatic 64 measured activity at 60,150 and 300 minutes after injection. For each examination, the patient's head was carefully placed in the apparatus in the same position. The change over time was estimated by calculating the ratio of activities (second measure/first measure) for each area of interest. Data were corrected for the physical decay of activity of the 99 Technetium, taking into account its half life (six hours)

4) Comparison with $C B F$ measured with ${ }^{133} \mathrm{Xe}$ Cerebral bloodflow was measured in eight patients, with the Tomomatic 64 , by continuous inhalation of ${ }^{133} \mathrm{Xe}$ (on the same tomographical slices)..$^{12}$ We analysed the CBF maps qualitatively (visually) and quantitatively as in the HMPAO study.

\section{Results}

1) Qualitative analysis of the tracer distribution A lesion was discovered in every patient at 10
(10 cases) or 60 minutes (10 cases). It was "certain" in 19 cases and "questionable" in one. In this case the haematoma was located in the periventricular area; the HMPAO hypoactivity was contiguous with the anterior horn of the lateral ventricle. This could explain the inconspicuous nature of the lesion.

Hypoactivity of the ipsilateral cortex was found in 19 cases ("questionable" in three). Frontal hypoactivity was principally observed with large lesions of the centrum semi ovalum (7/7 cases), but also with lesions that were judged to be capsulo-lenticular ( $3 / 5$ cases), capsulo-thalamic (4/4 cases) and thalamic (1/3 cases). Controlateral cerebellar hypoactivity (crossed diaschisis) was noted in 16/19 patients (questionable: one case). When this cerebellar hypoactivity was absent, the lesions were in the centrum semi ovalum (one case), in the lenticular nucleus (one case) or in the thalamus and internal capsule (one case).

2) Quantitative analysis of the tracer distribution Significant hypoactivity (AI $>0.04$ ) was noted 20 times in the area of the haematoma, 18 times in the ipsilateral cortex, and 11 times in the homolateral frontal cortex. Controlateral cerebellar hypoactivity was found in 15/19 cases.

The comparison between qualitative and quantitative analysis showed the results were very similar for all the areas of interest. Usually, the "questionable" hypoactivities revealed by visual examination were not associated with significant AI.

Furthermore, significant correlations were observed between the cortical and cerebellar AI (0.012), and strong interrelationships between the haematoma and cerebellar AI (0.036) and between the cortical and frontal AI (0.037).

3) Correlations between clinical data, the results of $C T$ and $A I$ ( HMPAO).

A significant correlation was observed between sensory leficit and the cortical AI (0.017), and a strong connection between motor deficit and the cortical AI (0.029). No correlation could be found between neuropsychological deficits and the AI. 


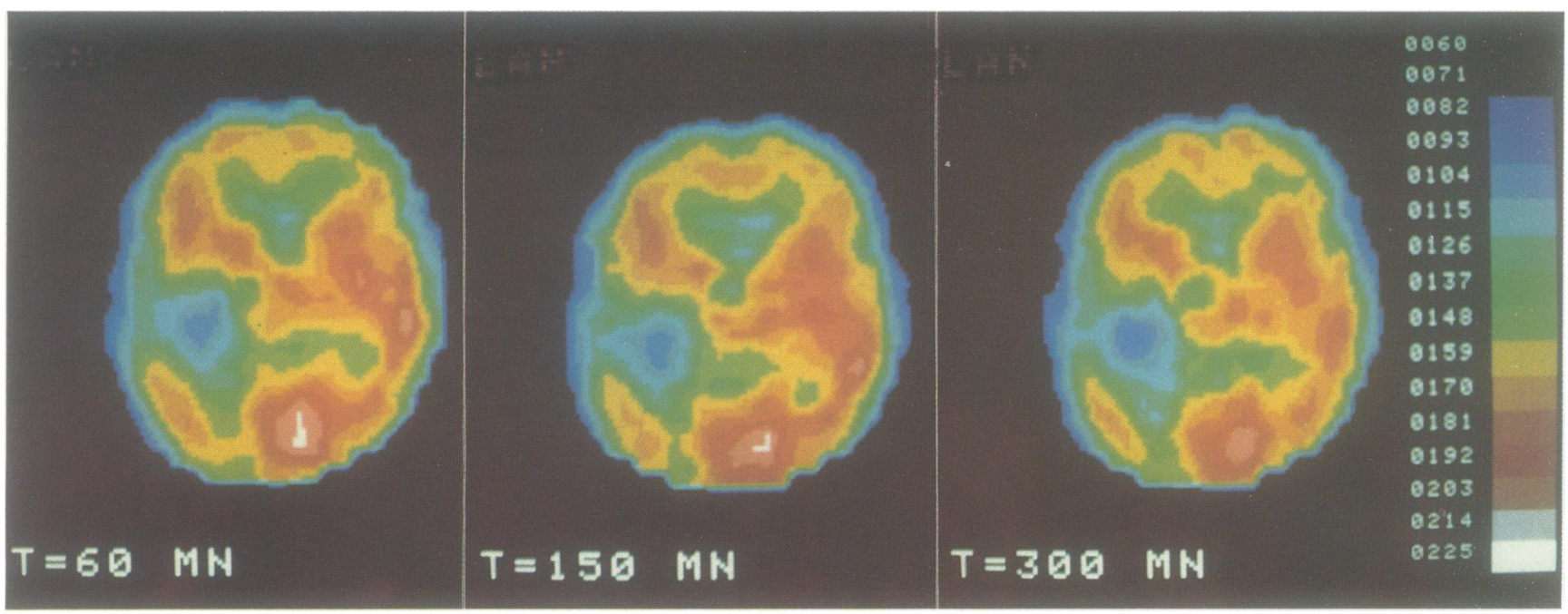

Figure 1 Evolution of the HMPAO distribution in a left capsulo lenticular haematoma. The tracer activity was stable over time.

\section{4) Analysis of the time course of $H M P A O$ activity \\ HMPAO activity was remarkably stable over} time (60, 150 and 300 minutes). No significant change could be noted, by quantitative analysis, at the level of the lesion, in the ipsilateral and frontal cortex, or in the cerebellum.

5) Comparison with the $C B F$ studies $\left({ }^{133} \mathrm{Xe}\right)$. In $8 / 8$ patients, the lesion was discovered by visual examination (questionable in one case). A decrease of the CBF was noted in six cases in the ipsilateral cortex, in six cases in the frontal cortex (questionable in three) and in eight in the cerebellum. The AI were less frequently significant $(>8 \%)$. Consequently, the relation between the "visual" and the "quantitative" analyses was better in the HMPAO study.

All the lesions displayed on the HMPAO maps were also seen with the ${ }^{133} \mathrm{Xe}$. Hypoactivity of the ipsilateral cortex was observed with both techniques. In one case, frontal hypoactivity was shown only by the ${ }^{133} \mathrm{Xe}$ study. Similar findings were present in two other cases with cerebellar hypoactivity.

\section{Discussion}

In each case, the lesion was identified by visual analysis. In most patients $(19 / 20)$, the cortex was not anatomically affected. The main area of hypoactivity shown by HMPAO was in good accord with the site of the haematoma visualised on the CT scan. Quantitative analysis

Figure 2 Evolution of the relative uptake (second measure(first measure) in 10 patients in the adjacent cortex, controlateral cerebellum, haematoma area and frontal ipsilateral cortex.

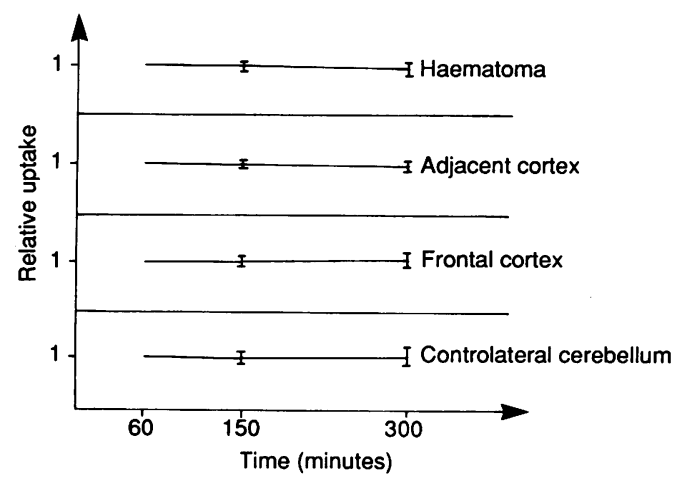

always confirmed the presence of a significant AI in the area of the lesion. This validated the visual analysis. The AI was less important in the thalamic and capsulo-thalamic haematomas: the small size of the lesions may account for this result.

A remote hypoactivity (diaschisis) was observed frequently, mainly in the ipsilateral non contiguous cortex, but also in the anterior frontal cortex and the controlateral cerebellum. We did not observe a paradoxal area of hyperaemia in the periphery of the lesion. Such a phenomenon has only been observed in cerebral infarctions at a very early stage after stroke; but in our series, only one patient was examined on the first day. The large haematomas of the centrum semi ovalum and nucleus lenticularis resulted most often in a frontal hypoactivity. This might be related to extension of the haematoma into the deep structures associated with the frontal lobe.

We believe that the result of an HMPAO study is useful in the identification of intracerebral haematomas and their remote effects. In this respect the data were comparable to the results of previous studies with ${ }^{133} \mathrm{Xe}$ and IAMP. ${ }^{1351314}$

Statistical analysis showed a significant correlation between the cortical and the cerebellar AI (HMPAO). This may indicate that hypoactivity of the controlateral cerebellum is the result of functional changes in the cerebral cortex, as seen with other techniques. ${ }^{15}$

Significant correlations were observed between the severity of the clinical neurological deficits and the cortical AI, but the Barthel's index was not correlated with the AI. We found similar results in a previous study with ${ }^{133} \mathrm{Xe}$ in patients with thalamic, capsulo-thalamic and lenticular haematomas. ${ }^{3}$ This is an interesting finding, because the cortical AI may be a good index of primary motor and sensory deficits. Other authors ${ }^{14}$ have suggested that remote hypoactivity was also related to the neuropsychological problems of the patients, but did not use a correlation procedure for their evaluations. Using ${ }^{133} \mathrm{Xe}$ to study $\mathrm{CBF}$ in patients with thalamic aphasia, ${ }^{16}{ }^{17}$ we also observed that 
the "severity" subtest of the Boston Diagnostic Aphasia Examination was not correlated with the AI of limited cortical areas. Caution is necessary in applying concepts such as cortical "deafferentation" or "diaschisis" to the mechanisms of the neuropsychological deficits associated with lesions of the basal ganglia and internal capsule.

Another interesting finding was the remarkable stability of the tracer over time in the lesion area, the perilesional area and the normal brain, when the primary values were corrected for the physical decrease of the activity of the 99 technetium. This stability or a very slow decline has already been described in the normal brain ${ }^{1819}$ and in subacute stroke. ${ }^{20}$

With IAMP, a late redistribution has been observed in cerebral haemorrhages and infarctions, ${ }^{62122}$ which has been considered to be an index of cellular viability. ${ }^{61}$ In a previous study of cerebral haemorrhages with IAMP ${ }^{22}$ our results contradicted this interpretation. Furthermore, Oba et $a l,{ }^{8}$ showed that the late IAMP redistribution is the result of a marked reduction in protein synthesis $(80 \%)$ and glucose metabolism $(20 \%)$. Our data with HMPAO and the previous findings of Andersen et $a l,{ }^{20}$ provide complementary arguments to support the absence of cellular viability in the area of the lesion. The results obtained with IAMP may reflect complex mechanisms. If the original distribution of IAMP is dependent on CBF, a redistribution may occur from passive diffusion across the altered blood-brain barrier, but also by a late capture of lipophilic IAMP metabolites of pulmonary origin. ${ }^{822}$

The stability of HMPAO is another argument for its simplicity of use as a tracer. About $5 \%$ of its total administered activity is fixed in the brain, and it reaches a stable level about three minutes after injection. From that time the cerebral output is less than $1 \%$ per hour. ${ }^{1823-25}$ This should allow delayed studies and cerebral tomography with the use of non specialised cameras which usually need long exposure times.

The HMPAO and the ${ }^{133} \mathrm{Xe} \mathrm{CBF}$ studies showed similar results in the haematoma area. The remote effects were sometimes discordant, more anomalies being revealed in the frontal lobe and cerebellum with ${ }^{133} \mathrm{Xe}$. The small number of patients, however, do not give a firm conclusion that the ${ }^{133} \mathrm{Xe}$ technique is superior.

In conclusion, this study demonstrated the usefulness of tomography with HMPAO in patients with an intracerebral hematoma, as already described in subarachnoid haemorrhages, ${ }^{26}$ cerebral tumours ${ }^{27}$ and focal epilepsy.

1 Kanaya H, Endo H, Sugiyama T, Kuroda K. "Crossed cerebellar diaschisis" in patients with putaminal hemorrhage. J CBF Metabol 1983;8(Suppl 1):527.
2 Meyer JS, Okayasu H, Tachibana H, Okabe T. Stable xenon CT CBF measurements in prevalent cerebrovascular disorders (stroke). Stroke 1984;15:80-90.

3 Rousseaux M, Steinling M, Petit H, Lesoin F, Dubois F, Vergnes $R$. Perturbations du débit sanguin hémisphèrique et hématomes cérébraux profonds. Rev Neurol 1986; 142:480-8.

4 Steinling M, Mazingue A, Rousseaux M, Destée A, Blanc D, Warot $P$, Vergnes $R$. Mesure tomographique de la distribution de la $\mathrm{N}$-isopropyl-P-123 iodo-amphetamine en pathologie vasculaire cérébrale. Comparaison avec la mesure par inhalation de Xenon 133. Acta Neurol Belg 1987;87:113-24.

5 Perani D, Vallar G, Cappa S, Messa C, Fazio F. Aphasia and neglect after subcortical stroke. A clinical/cerebral perfusion correlation study. Brain 1987;110:1211-29.

6 Raynaud C, Rancurel G, Samson Y, et al. Measurement of oxygen metabolism, 123 I-AMP distribution and CBF Xe in patients with ischemic vascular disease. $J$ Nucl Med 1983;24:8.

7 Steinling $M$, Mazingue A, Rousseaux M, Duhamel A, Dubois $P$, Vergnes R. Suivi séquentiel de la distribution de 123-iodoamphetamine dans les hémorragies intracraniennes: comparaison avec les infarctus cérébraux. $J$ Biophis Biomecan 1987;11(Suppl 1):17-19.

8 Oba H, Matsuda H, Tsuji S, et al. Relationship between IMP redistribution and metabolism in experimental brain ischemia. J CBF Metabol 1989;9(Suppl 1):423.

9 Steinling M, Mazingue A, Kassiotis P, et al. Le HmPAO Tc comme indicateur du débit sanguin cérébral local: Etude quantifiée comparé à la méthode par inhalation au Xén 133. Ann Radiol 1988;31:229-38.

10 Mahoney FI, Barthel DW. Functional evaluation: Barthel index. M D State J 1965;14:61-5.

11 Diaconis $P$. Theories of data analysis: From magical thinking through classical statistics. In: Hoaglin DC, Mosteller F, Tukey JW, eds. Exploring data tables, trends, and shapes. Tukey JW, eds. Exploring da

12 Stokely EM, Sveinsdottir E, Lassen NA, Rommer P. A single photon dynamic computer assisted tomograph (D CAT) for imaging brain function in multiple cross sections. J Comput Assist Tomogr 1980;4:230-40.

13 Skyhoj Olsen T, Bruhn P, Oberg RGE. Cortical hypoperfusion as a possible cause of "subcortical aphasia". Brain 1986;109:393-410.

14 Baron JC, D'Antona R, Serdaru M, Pantano P, Bousser MG, Samson Y. Hypometabolisme cortical après lésion thalamique chez l'homme: étude par la tomographie à positions. Rev Neurol 1986;142:465-74.

15 Pantano P, Baron JC, Bousser MG, Derouesne C, Comar D. Crossed cerebellar diaschisis: further studies. Brain 1986;109:677-94.

16 Rousseaux M, Griffie G, Quint S, et al. Correlations between local $\mathrm{CBF}$ and linguistic data in 20 thalamic aphasias. CBF Metabol 1989;9(Suppl 1):347.

17 Rousseaux M, Steinling M, Griffié G, et al. Corrélations de l'aphasie thalamique avec le débit sanguin cérébral. Rev Neurol 1990;146:345-53.

18 Costa DC, Ell PJ, Cullum ID, Jarritt PM. The in vivo distribution of $99 \mathrm{~m} \mathrm{Tc-HmPaO}$ in normal man. Nucl Med Comm 1986;7:647-58.

19 Podreka I, Suess E, Goldenberg G, et al. Initial experience with Technetium-99m HM-PAO Brain SPECT. J Nucl Med 1987;28:1657-66.

20 Andersen A, Hasselbalch SG, Lassen NA, Kristensen $K$ Paulson OB, Neirinckx RD. Tc-99m-HMPAO d, imaging of CBF: a comparison with Xenon-133. J CBF Metabol 1987;7(Suppl 1):559.

21 Creutzig H, Schober O, Gielow P, et al. Cerebral dynamics of N-Isopropyl-(123I)P-Iodoamphetamine. J Nucl Med 1986;27:178-83.

22 Steinling M, Mazigue A, Rousseaux M, et al. Sequentia follow up of the 123 IAMP distribution in the human haemorrhagic brain. Nucl Med 1987;26:150

23 Holmes RA, Chapin SB, Royston KG, Volkert WA Nowotnik DP. Cerebral uptake and retention of $99 \mathrm{~m}$ TcHexamethylpropylene Amine Oxime (Tc- $\mathrm{Hm}-\mathrm{PaO}$ ) Nucl Med Comm 1985;6:443-7.

24 Neirinckx RD, Canning LR, Piper IM. Technetium $99 \mathrm{~m}$ d, 1, HmPaO: A new radiopharmaceutical for SPECT imaging of regional cerebral blood perfusion. J Nucl Med 1987;28:191-202.

25 Steinling M, Kassiotis P, Lassen N. Redistribution tardive du HMPAO-Tc: Quand? Pourquoi? Circ Metabol du HMPAO-Tc: Quand

26 Rawlik D, Smith FW, Deans HE, Gemmell HG, MacDonald AF. Technetium 99m HMPAO scanning in patients with subarachnoid haemorrhage: A preliminary study. Brit J Radiol 1988;61:26-9.

27 Babich JW, Keeling F, Flower MA, et al. Initial experience with Tc-99m-HM-PAO in the study of brain tumours. Eur J Nucl Med 1988;14:39-44. 